\title{
Relationship between Dysphagia and Exacerbations in Chronic Obstructive Pulmonary Disease: A Literature Review
}

\author{
Eduardo Steidl ${ }^{1}$ Carla Simone Ribeiro ${ }^{2}$ Bruna Franciele Gonçalves ${ }^{1}$ Natália Fernandes ${ }^{3}$ \\ Vívian Antunes $^{2}$ Renata Mancopes ${ }^{3}$
}

1 Post-Graduation Student, Department of Speech Therapy, Universidade Federal de Santa Maria, Santa Maria, RS, Brazil

${ }^{2}$ Department of Physiotherapy, Centro Universitário Franciscano, Santa Maria, RS, Brazil

${ }^{3}$ Department of Speech Therapy, Universidade Federal de Santa Maria, Santa Maria, RS, Brazil

Int Arch Otorhinolaryngol 2015;19:74-79.
Address for correspondence Eduardo Steidl, Physical Therapist, PostGraduation Student, Universidade Federal de Santa Maria, Santa Maria, RS 97105-900, Brazil (e-mail: edumatias2005@gmail.com).

\begin{abstract}
Keywords

- pulmonary disease

- deglutition

- deglutition disorders

Introduction The literature presents studies correlating chronic obstructive pulmonary disease to dysphagia and suggesting that the aspiration laryngeal phenomenon related to changes in the pharyngeal phase contributes significantly to the exacerbation of symptoms of lung disease.

Objectives This study aimed to conduct a literature review to identify the relation between dysphagia and exacerbations of chronic obstructive pulmonary disease.

Data Synthesis We found 21 studies and included 19 in this review. The few studies that related to the subject agreed that the presence of dysphagia, due to lack of coordination between swallowing and breathing, may be one of the triggering factors of chronic obstructive pulmonary disease exacerbation.

Conclusions The review noted that there is a relationship between dysphagia and exacerbations of chronic obstructive pulmonary disease, identified by studies demonstrating that the difficulties associated with swallowing may lead to exacerbation of the disease. There was difficulty in comparing studies by their methodological differences. More research is needed to clarify the relationship between dysphagia and exacerbations of chronic obstructive pulmonary disease, making it possible to develop multiprofessional treatment strategies for these patients, catered to specific needs due to the systemic manifestations of the disease.
\end{abstract}

\section{Introduction}

Chronic obstructive pulmonary disease (COPD) is characterized by chronic airflow limitation leading to pathologic alterations in the lungs with consequent extrapulmonary effects. It is not a completely reversible disease, generating systemic complications and comorbidities that contribute to the worsening of the disease and that can lead to death. ${ }^{1,2}$
Its principal etiologic factors include the inhalation of particles or gases; exposure to smoking, occupational dust, chemical irritants; and socioeconomic conditions, among others. ${ }^{3}$

One symptom manifested by COPD is coughing, which can occur daily or intermittently, and another is dyspnea, which is associated with disability in activities of daily living and decreased quality of life, progressing as the disease worsens. ${ }^{4}$ received

October 31, 2013

accepted

April 1, 2014

published online

November 6, 2014
DOI http://dx.doi.org/

10.1055/s-0034-1376430. ISSN $1809-9777$.
Copyright $(2015$ by Thieme Publicações License terms

Ltda, Rio de Janeiro, Brazil
()(1) $\Theta \circledast$ 
These factors exacerbate the disease, because they result in worse gas exchange and pulmonary hemodynamics.

Furthermore, COPD might affect the dynamics and coordination of other important functions such as deglutition. ${ }^{5}$ Deglutition is considered both a dynamic and a complex process; it has the function of transporting the bolus from the mouth to the stomach in a safe manner. At the time the food is swallowed, a pause in breathing occurs for a few seconds, and the breath returns in the expiratory phase, thereby avoiding aspiration episodes. ${ }^{6}$

Difficulties resulting from respiratory and/or ventilatory pattern might alter this coordination, resulting in decreased protection of the lower airway as may occur in patients with COPD due to ventilatory functional alterations and thoracoabdominal biomechanics, which can lead to difficulties in swallowing process called dysphagia. ${ }^{5}$ Dysphagia refers to changes during swallowing, which may involve any of the stages of this process; however, the alteration of the pharyngeal phase of swallowing might result in the entry of food into the airway, causing laryngeal penetration, laryngotracheal aspiration, pulmonary problems, undernutrition, dehydration, or aspiration pneumonia and might even lead to death. ${ }^{7-9}$

The literature presents studies that relate COPD to dysphagia, suggesting that the laryngeal aspiration phenomenon, related to the alteration in the pharyngeal phase of swallowing, contributes significantly to the exacerbation of the symptoms of lung disease, ${ }^{6,10}$ in addition to causing more frequent hospitalizations. ${ }^{11}$ Abnormalities in the swallowing process are associated with frequent exacerbations in patients with COPD. ${ }^{12}$ However, it is unclear whether these abnormalities may already be found in patients with mild degree of disease. ${ }^{13}$

It is known that adequate protective reflexes of the airway have an important role in the aspiration prevention, whereas the impairment in the swallowing reflex may become a potential risk factor for exacerbations of COPD. ${ }^{10}$

The purpose of this literature review was to investigate the relation between dysphagia and exacerbations of COPD.

\section{Methods}

The National Library of Medicine (Medline), Library Online (SciELO), Literatura Latino-Americana e do Caribe (Lilacs), Physiotherapy Evidence Database (PEDro), and U.S. National Library of Medicine National Institutes of Health (PubMed) databases were searched for articles published from November 2012 to March 2013. Search descriptors "DPOC," "Deglutição," and "Transtornos de Deglutição" and their corresponding English "pulmonary disease," "deglutition," and "deglutition disorders" were used. The search was limited to Portuguese and English languages and studies performed with adults with COPD of both genders, published between 2000 and 2013. Studies outside the stipulated period were excluded. Titles and abstracts were analyzed to obtain potentially relevant articles for review and in accordance with the proposed purpose in the present study.

From the methodology applied, 16 studies were found, of which 14 were included in this review. The reviewed articles were organized in the following categories: (1) considerations about the COPD and (2) dysphagia and exacerbations in COPD.

\section{Literature Review}

\section{Considerations in Chronic Obstructive Pulmonary Disease}

The World Health Organization estimates that through 2030 the mortality and disability caused by COPD will increase significantly. Estimates suggest that $\sim 5.5$ million people have the disease in Brazil, and it is a major cause of deaths in the country. Tobacco use is responsible for 80 to $90 \%$ of cases, ${ }^{14}$ and its chronic use is associated with decreased pulmonary function. In addition to cigarette smoke, inhalation of particles and toxic gases, such as smoke from the firewood, irritating gases, and occupational exposure, have a direct relation to the development and maintenance of airway obstruction. $^{15}$

For pneumology and physical therapy, the gold standard instrument for disease diagnosis is spirometry, which observes the restriction to airflow before and after bronchodilator use. The most important parameters in view of clinical application are the forced vital capacity (FVC), forced expiratory volume in 1 second $\left(\mathrm{FEV}_{1}\right)$, and $\mathrm{FEV}_{1}$-to-FVC ratio. The $\mathrm{FEV}_{1}$-to-FVC ratio after bronchodilator must be reduced (i.e., less than $80 \%$ predicted). ${ }^{16}$

The degree of severity of the disease is determined by clinical characteristics and the airflow limitation. Mild COPD (stage I) is characterized by mild airflow limitation $\left(\mathrm{FEV}_{1} /\right.$ FVC $<70 \%$, but $\mathrm{FEV}_{1} \geq 80 \%$ of predicted), and at this stage the individual may not be aware that their lung function is abnormal; moderate COPD (stage II) occurs with worsening of airflow limitation $\left(30 \% \geq \mathrm{FEV}_{1}<70 \%\right.$ of predicted and $\mathrm{FEV}_{1} \geq 80 \%$ of predicted), and dyspnea becomes more intense to efforts; in severe disease (stage III), $\mathrm{FEV}_{1} / \mathrm{FVC}<70 \%$ or $\mathrm{FEV}_{1}>50 \%$ of predicted plus respiratory insufficiency or clinical signs of right ventricular failure are evident. ${ }^{16}$

The concept of COPD involves two entities, pulmonary emphysema and chronic bronchitis. Pulmonary emphysema may be defined as a chronic obstructive process, resulting in important alterations to the whole structure distal to the terminal bronchioles, called lobes, leading to accumulation of air in the lungs, condition called pulmonary hyperinflation. ${ }^{17}$

Already chronic bronchitis is a clinical condition characterized by excessive secretion in the bronchial tree, the presence of chronic or recurrent cough, with expectoration for the least 3 consecutive months of the year and 2 consecutive years. ${ }^{18}$ Physiopathology of chronic bronchitis involves the destruction of the lung parenchyma, causing pulmonary hyperinflation that leads to increased airflow obstruction and reduced lung elastic recoil. ${ }^{19,20}$ Hyperinflation, due to alterations of the respiratory muscles, interferes in diaphragmatic excursion, which modifies the disposition of thoracic wall, ${ }^{21}$ reflecting an abnormal movement between the thorax and abdomen.

The mechanical disadvantage found in patients with COPD leads to recruitment of accessory muscles of inspiration and 
compromises diaphragm performance, which becomes rectified and decreases apposition area, thereby restricting its excursion. ${ }^{22}$ Wouters emphasized that the clinical manifestations of COPD extend beyond the lung issues, given the impact on general health by the influence of systemic manifestations, such as the incoordination of the swallowing function. $^{23}$

\section{Dysphagia and Exacerbations in Chronic Obstructive Pulmonary Disease}

Swallowing is didactically divided into four phases: oral preparatory, proper oral, pharyngeal, and esophageal. The first two stages correspond to the preparation of food in the oral cavity by chewing (incision, mastication, and pulverization), associated with saliva to form the alimentary bolus, and the transport of the alimentary bolus toward the pharynx. In the pharyngeal phase, food is transported to the esophagus and involves a series of involuntary events for protection of the lower airway, which is the most important phase. The esophageal phase corresponds to the bolus transport to the stomach. $^{24}$

Dysphagia is characterized by any difficulty during the swallowing stage that prevents the proper conduct of the alimentary bolus from the oral cavity to the stomach. ${ }^{9}$ To verify the presence and severity of the swallowing disorder, after clinical evaluation speech-language pathologists often classify the swallowing dynamics according to the occurrence of clinical findings. The Dysphagia Risk Evaluation Protocol classifies swallowing at different levels ranging from level I (normal swallowing) to level VII (severe dysphagia); speechlanguage treatment is performed according to classification. ${ }^{25}$

It is noteworthy that dysphagia is not only detected by clinical evaluation due to the absence of clinical signs; sometimes it is necessary to objectively examine swallowing to verify aspirations that occur silently, with videofluoroscopy as the gold standard examination in this case. ${ }^{26}$

The lack of coordination of these movements is related to the presence of laryngeal penetration (i.e., the entry of secretions, food, or liquid above the level of the vocal folds and/or laryngotracheal aspiration, which happens with entry of any substance below the level of the vocal folds and can lead to aspiration pneumonia). ${ }^{5,26}$ Subjects with COPD are more susceptible to present this dyssynchrony. ${ }^{5}$

COPD has the potential to alter the coordination between swallowing and breathing due to dyspnea and abnormalities of thoracoabdominal biomechanics, which negatively influences the normal process of swallowing of these individuals; they do not realize the respiratory pause that is observed in a process of normal swallowing, increasing the risk of penetration of the content into the pharynx. ${ }^{27}$ Some authors suggest that the presence of dysphagia may be one factor that initiates the exacerbation of COPD, especially when the incoordination of the swallowing reflex occurs with consequent laryngeal aspiration. ${ }^{10,28}$

Exacerbations characterize the acute worsening of COPD symptoms, accelerating the decline in lung function and compromising the quality of life of patients, ${ }^{29,30}$ because they increase the demand for doctor visits, hospitalization, and treatment costs. They can also contribute to airway inflammation and may present incomplete recovery and contribute to the decline of $\mathrm{FEV}_{1}$, which in these patients is already at reduced values. ${ }^{31,32}$

Proper coordination between breathing and swallowing events is essential for human survival, ensuring effective hydration and nutrition and preventing pulmonary aspiration. ${ }^{33}$ Dysphagia may be the result of various disorders and diseases. Respiratory impairment itself leads the individual to have a higher energy expenditure, which can lead to weight loss and undernutrition. Swallowing disorders can also lead to other complications, including dehydration, aspiration pneumonia, or airway obstruction. ${ }^{34}$

Strength and respiratory muscle endurance are reduced in patients with COPD, because of hyperinflation, poor nutrition, and general deconditioning of the muscles that lead to increased work of breathing. ${ }^{35}$ The systemic effects of the disease go beyond the lung impairments. Pulmonary obstruction is caused by different pathophysiological factors that lead to hyperinflation of the lung. ${ }^{36}$

Decline in lung function leads to diaphragmatic mobility reduction, ${ }^{37}$ and changes in diaphragmatic excursion alter the provision of thoracic wall, causing reverberating abnormal movement between the thorax and abdomen. Patients with COPD commonly use the accessory muscles of respiration, which shortens the muscles and makes them tense. This change may reflect the disposition of the larynx and even the pharynx, damaging the effective process of swallowing.

In a systematic review of the literature conducted by O'Kane and Groher, six of the seven studies surveyed documented some kind of alteration in the swallowing process of patients with COPD. ${ }^{6}$ Insufficient swallowing accompanied by pulmonary aspiration may be a predictive factor for exacerbations in patients with COPD. In the same way, disease exacerbations may be precursors of poor swallowing, suggesting alteration in the swallowing reflex during exacerbations of the disease. ${ }^{38}$

\section{Discussion}

COPD is a lung disease that affects $12 \%$ of the population, occurs in subjects mainly older than 40 years of both genders, and is the fourth to seventh leading cause of death in Brazil. $^{21,39}$ It is considered a public health problem that is growing every year. In Brazil, studies related to COPD epidemiology are scarce when compared with international studies, but the number of deaths from the disease has been increasing in the past 20 years, for both genders; mortality based on cause of disease increased $\sim 340 \%$. ${ }^{40}$

Smoking is a leading cause of COPD, with the frequency of cigarette consumption associated with greater impairment of lung function and consequent airflow limitation. ${ }^{21}$ Soares et al aimed to characterize the population to the risk of COPD and found that in a sample of 157 subjects, 108 (68,8\%) were male with a mean age of 53.85 years; the researchers also found that the greater amount of cigarettes smoked predominated in this sex. ${ }^{3}$ This finding highlights the need to 
perform early intervention in this population, to prevent the development and consequences of long-term COPD.

Some authors suggest that the clinical manifestations of COPD may affect other important functions such as swallowing, which is justified by the incoordination during apnea of respiration when food passes through the pharynx. ${ }^{28}$ The pharyngeal phase of swallowing is considered the most important, because there are many occurrences necessary for directing the alimentary bolus movements, such as elevation and anterior displacement of the larynx, firm glottal closure and lowering of the epiglottis, along with breathing apnea; that there should be a synchronism in that movement so that the aliment is not diverted toward the lower airway. ${ }^{25}$

Drozdz et al analyzed the pharyngeal phase of swallowing in subjects with chronic cough using videofluoroscopy. ${ }^{41}$ They found that mild dysphagia occurred in $20 \%$ of cases and $13.4 \%$ had mild to moderate or moderate dysphagia. They concluded that this population, despite not presenting swallowing complaints, has higher aspiration risk due to alteration in breathing pattern that could lead to lack of coordination between swallowing and breathing.

Bastille et al compared the results of clinical and objective evaluation of swallowing of a subject diagnosed with COPD. ${ }^{42}$ They found that the clinical evaluation of swallowing was normal; however, due to the presence of chronic cough, videofluoroscopy showed the presence of laryngeal penetration of the laryngotracheal aspiration, which was silent due to the decreased sensitivity of the laryngeal region.

In this context, several studies have shown the relation of dysphagia with disease exacerbation in patients with COPD. In one of these studies, a self-perception questionnaire was used, and 35 patients in clinical and medication treatment reported the presence of dysphagia in the pharyngeal and esophageal phases of swallowing. ${ }^{5}$

One study of 61 patients with no history of COPD exacerbations in the previous 4 weeks, using the repetitive saliva swallowing test (RSST) and the modified water-swallow test, showed that dysphagia causes exacerbations in COPD subjects; the RSST test was useful for dysphagia detect associated with exacerbations. ${ }^{43}$ Similar findings were found in 2009 , when 64 patients with COPD were tested with the simple two-step swallowing provocation test and the RSST; swallowing dysfunction could be observed in the mild stage of the disease. $^{13}$

In research conducted in 2007, 50 patients with COPD were evaluated based on the response latency time of the swallowing reflex, timed from the instillation of 0.03 ounces of distilled water to the pharynx through a nasal catheter; results indicated impairments in this reflex, which was significantly associated with disease exacerbation. ${ }^{10}$ Similar results were observed in a 2010 study, when 65 patients with COPD who had episodes of exacerbation recorded over a period of 12 months were assessed using a self-perception questionnaire; results showed altered swallowing reflex that could predispose them to disease exacerbations. ${ }^{12}$

Videofluoroscopy was used to evaluate 16 patients, and results suggested that impairments in swallowing may occur when there is ingestion of large quantities of liquids. Still, the authors suggested possible association of respiratory pattern with swallowing disorders. ${ }^{44}$ Similar results were evidenced in 2002 in a study that also used videofluoroscopy to evaluate patient swallowing, which concluded that these patients had abnormal physiology of swallowing. ${ }^{45}$

Gross et al in their study found that patients with COPD had alterations between the process of breathing and swallowing, and this alteration may increase the risk of pulmonary aspiration contributing to disease exacerbations. ${ }^{28}$ The evaluation used respiratory inductance plethysmography to track respiratory signs, as well as the electromyography to score the behavior of the act of swallowing during each respiratory cycle.

McKinstry et al observed that alterations in the respiratory mechanics of COPD commonly include swallowing disorders. ${ }^{46}$ Research indicates that people with the disease have a propensity to develop oropharyngeal dysphagia as a consequence of the lack of coordination between breathing and swallowing.

In research conducted by Mokhlesi et al, the starting point was the hypothesis that patients with COPD have a lower rest position and reduced larynx elevation, which increases the risk of aspiration. ${ }^{45}$ Videofluoroscopy may show these patients have abnormal swallowing, but more studies are needed to assess the aspirations as a cause of exacerbations.

Previous studies have cited these findings, noting that reduced laryngeal elevation occurs during the swallowing process and alterations of the cricopharyngeal muscle. The literature describes that this dysphagia in these patients is related to the lack of coordination between breathing and swallowing. ${ }^{33}$ In a study of 78 patients with COPD, we observed that $85 \%$ of them had some degree of dysphagia. ${ }^{19}$

In a study performed with patients with COPD and gastroesophageal reflux disease, patients who had daily or weekly symptoms were more prone to exacerbations of the disease, which may occur due to microaspirations of gastric contents leading to irritation of the airways. Another mechanism would be to increase intra-abdominal pressure generated by hyperinflation and increased respiratory effort, which alters the relation between the diaphragm and the esophageal sphincter. ${ }^{47}$

Thus, it is evident that early detection of the presence of dysphagia, mainly related to lack of coordination between the functions of swallowing and breathing in subjects with COPD, may assist in decreasing the disease exacerbation.

\section{Conclusion}

In this review, a relationship between the presence of dysphagia and exacerbations of COPD was noted, as identified by studies demonstrating that the difficulties associated with swallowing might lead to disease exacerbations. There seems to be a consensus among authors concerning this relation, so that the main factor for this occurrence is related by the lack of coordination between the functions of breathing and swallowing, because subjects with COPD do not perform adequately apnea of breath. However, it was difficult to compare the studies because methodological differences. 
More research to clarify the relation between dysphagia and exacerbations of COPD is needed; it might then possible to search multidisciplinary strategies to assist in the treatment of these patients in a comprehensive manner, to cater treatment to their specific needs due to systemic manifestations of pulmonary disease.

\section{References}

1 Ferrari R, Tanni SE, Faganello MM, Caram LM, Lucheta PA, Godoy I. Three-year follow-up study of respiratory and systemic manifestations of chronic obstructive pulmonary disease. Braz J Med Biol Res 2011;44(1):46-52

2 Fabbri LM, Luppi F, Beghé B, Rabe KF. Update in chronic obstructive pulmonary disease 2005. Am J Respir Crit Care Med 2006;173(10): 1056-1065

3 Soares S, Costa I, Neves AL, Couto L. Characterisation of a population at increased risk of COPD. Rev Port Pneumol 2010;16(2): 237-252

4 Camargo LACR, Pereira CAC. Dyspnea in COPD: beyond the modified medical research council scale. J Bras Pneumol 2010;36(5): 571-578

5 Chaves RdeD, Carvalho CRF, Cukier A, Stelmach R, Andrade CRF. Symptoms of dysphagia in patients with COPD. J Bras Pneumol 2011;37(2):176-183

6 O'Kane L, Groher M. Dysphagia and obstructive pulmonary disease: a systematic review. Rev CEFAC 2009;11(3):499-506

7 Santoro PP, Furia CL, Forte AP, et al. Otolaryngology and speech therapy evaluation in the assessment of oropharyngeal dysphagia: a combined protocol proposal. Braz J Otorhinolaryngol 2011; 77(2):201-213

8 van der Kruis JG, Baijens LW, Speyer R, Zwijnenberg I. Biomechanical analysis of hyoid bone displacement in videofluoroscopy: a systematic review of intervention effects. Dysphagia 2011;26(2): 171-182

9 Abdulmassih EMS, Macedo Filho ED, Santos RS, Jurkiewicz AL. Evolution of patients with oropharyngeal dysphasia in hospital environment. Intl Arch Otorhinolaryngol 2009;13(1):55-62

10 Kobayashi S, Kubo H, Yanai M. Impairment of the swallowing reflex in exacerbations of COPD. Thorax 2007;62(11):1017

11 Rodríguez-Roisin R. COPD exacerbations. 5: Management. Thorax 2006;61(6):535-544

12 Terada K, Muro S, Ohara T, et al. Abnormal swallowing reflex and COPD exacerbations. Chest 2010;137(2):326-332

13 Ohta K, Murata K, Takahashi T, Minatani S, Sako S, Kanada Y. Evaluation of swallowing function by two screening tests in primary COPD. Eur Respir J 2009;34(1):280-281

14 Cavalcante AG, de Bruin PF. The role of oxidative stress in COPD: current conceptsand perspectives. J Bras Pneumol 2009;35(12): 1227-1237

15 Bargatin E, Jardin JR, Stirbulov R. Occupational chronic obstructive pulmonary disease. J Bras Pneumol 2006;32(Suppl 2):35-40

16 GOLD-Global Initiative for Chronic Obstructive Lung Disease. 2006. Available at: http://www.goldcopd.org. Accessed May 5, 2013

17 Barnes PJ. Chronic obstructive pulmonary disease. N Engl J Med 2000;343(4):269-280

18 Gonzaga FMG, Velloso M, Almeida PS. Análise do fisioterapeuta no paciente com bronquite crônica na fase hospitalar. In: IX Encontro Latino Americano de Iniciação Científica e V Encontro Latino Americano de Pós-Graduação, UNIVAP: Paraíba 2005; 1648-1651

19 Good-Fratturelli MD, Curlee RF, Holle JL. Prevalence and nature of dysphagia in VA patients with COPD referred for videofluoroscopic swallow examination. J Commun Disord 2000;33(2):93-110
20 Rogha M, Behravesh B, Pourmoghaddas Z. Association of gastroesophageal reflux disease symptoms with exacerbations of chronic obstructive pulmonary disease. J Gastrointestin Liver Dis 2010; 19(3):253-256

21 Dourado VZ, Tanni SE, Vale SA, Faganello MA, Sanchez FF, Godoy I. Systemic manifestations in chronic obstructive pulmonary disease. J Bras Pneumol 2006;32(2):161-171

22 Trevisan ME, Porto AS, Pinheiro TM. Influence of respiratory and lower limb muscle training on functional performance of subjects with COPD. Fisioter Pesqui 2010;17(3):209-213

23 Wouters EF. Local and systemic inflammation in chronic obstructive pulmonary disease. Proc Am Thorac Soc 2005;2(1):26-33

24 Matsuo K, Palmer JB. Anatomy and physiology of feeding and swallowing: normal and abnormal. Phys Med Rehabil Clin N Am 2008;19(4):691-707, vii

25 Padovani AR, Moraes DP, Mangili LD, Andrade CRF. Protocolo Fonoaudiológico de Avaliação do Risco para Disfagia (PARD). J Soc Bras Fonoaudiol 2007;12(3):199-205

26 Dozier TS, Brodsky MB, Michel Y, Walters BC Jr, Martin-Harris B. Coordination of swallowing and respiration in normal sequential cup swallows. Laryngoscope 2006;116(8):1489-1493

27 Singh B. Impaired swallow in COPD. Respirology 2011;16(2): 185-186

28 Gross RD, Atwood CW Jr, Ross SB, Olszewski JW, Eichhorn KA. The coordination of breathing and swallowing in chronic obstructive pulmonary disease. Am J Respir Crit Care Med 2009;179(7): 559-565

29 Hurst JR, Vestbo J, Anzueto A, et al; Evaluation of COPD Longitudinally to Identify Predictive Surrogate Endpoints (ECLIPSE) Investigators. Susceptibility to exacerbation in chronic obstructive pulmonary disease. N Engl J Med 2010;363(12):1128-1138

30 Yawn BP. Early identification of exacerbations in patients with chronic obstructive pulmonary disease. J Prim Care Community Health 2013;4(1):75-80

31 Donaldson GC, Seemungal TAR, Bhowmik A, Wedzicha JA. Relationship between exacerbation frequency and lung function decline in chronic obstructive pulmonary disease. Thorax 2002; 57(10):847-852

32 Han MK, Kazerooni EA, Lynch DA, et al; COPDGene Investigators. Chronic obstructive pulmonary disease exacerbations in the COPDGene study: associated radiologic phenotypes. Radiology 2011;261(1):274-282

33 Martin-Harris B, Brodsky MB, Price CC, Michel Y, Walters B. Temporal coordination of pharyngeal and laryngeal dynamics with breathing during swallowing: single liquid swallows. J Appl Physiol (1985) 2003;94(5):1735-1743

34 Ferreira IM. Chronic obstructive pulmonary disease and malnutrition: why are we not winning this battle? J Bras Pneumol 2003; 29(2):107-115

35 Sturdy G, Hillman D, Green D, Jenkins S, Cecins N, Eastwood P. Feasibility of high-intensity, interval-based respiratory muscle training in COPD. Chest 2003;123(1):142-150

36 Celli BR, MacNee W; ATS/ERS Task Force. Standards for the diagnosis and treatment of patients with COPD: a summary of the ATS/ERS position paper. Eur Respir J 2004;23(6):932-946

37 Yamaguti WPS, Paulin E, Salge JM, Chammas MC, Cukier A, Carvalho CRF. Diaphragmatic dysfunction and mortality in patients with COPD. J Bras Pneumol 2009;35(12):1174-1181

38 Robinson DJ, Jerrard-Dunne P, Greene Z, Lawson S, Lane S, O'Neill D. Oropharyngeal dysphagia in exacerbations of chronic obstructive pulmonary disease. Eur Ger Med 2011;2(4):201-203

39 Sociedade Brasileira de Pneumologia e Tisiologia. II Consenso Brasileiro sobre Doença Pulmonar Obstrutiva Crônica-DPOC. J Bras Pneumol 2004;30(Suppl 5):S1-S42

40 Pessoa CLC, Pessoa RS. Epidemiologia da DPOC no presenteaspectos nacionais e internacionais. Pulmão RJ 2009;1(1):7-12 
41 Drozdz DRC, Costa CC, Jesus PRO, et al. Pharyngeal swallowing phase and chronic cough. Int Arch Otorhinolaryngol 2012;16(4): 502-508

42 Bastilha GR, Rocha RM, Gonçalves BFT, Bilheri DFD. Results of clinical evaluation and objective of swallowing in patients with chronic cough: case report. Int Arch Otorhinolaryngol 2012;16 (Suppl 1):98

43 Tsuzuki A, Kagaya H, Takahashi H, et al. Dysphagia causes exacerbations in individuals with chronic obstructive pulmonary disease. J Am Geriatr Soc 2012;60(8): $1580-1582$
44 Cvejic L, Harding R, Churchward T, et al. Laryngeal penetration and aspiration in individuals with stable COPD. Respirology 2011; 16(2):269-275

45 Mokhlesi B, Logemann JA, Rademaker AW, Stangl CA, Corbridge TC. Oropharyngeal deglutition in stable COPD. Chest 2002;121(2): 361-369

46 McKinstry A, Tranter M, Sweeney J. Outcomes of dysphagia intervention in a pulmonary rehabilitation program. Dysphagia 2010;25(2):104-111

47 Donaldson GC, Wedzicha JA. COPD exacerbations. 1: Epidemiology. Thorax 2006;61(2):164-168 